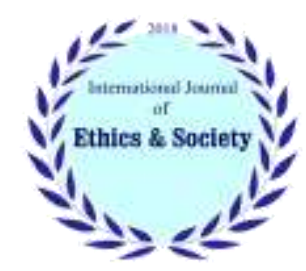

International Journal of Ethics \& Society (IJES)

Journal homepage: $\underline{\text { www.ijethics.com }}$

Vol. 3, No. 1 (2021)

(Original article)

\title{
Relationship between Participatory Ethical Culture \& Evaluating the Performance of Knowledge Employees \& Its Outputs
}

\section{Barbod Shabaninezhad Kisomi ${ }^{a}$, Sanjar Salajegheh ${ }^{b^{*}}$, Alireza Manzari ${ }^{c}$, Mohammad Jalalkamali ${ }^{b}$}

a) PhD Student, Dept. of Management, Kerman Branch, Islamic Azad University, Kerman, Iran
b) Dept. of Management, Kerman Branch, Islamic Azad University, Kerman, Iran
c) Department of Educational Sciences \& Psychology, Azad University of Kerman, Kerman, Iran

\section{Abstract}

Background: The purpose of this study is to analyze the relationship between participatory ethical culture and evaluating the performance of knowledge employees and its outputs in knowledge-based companies in Tehran. Method: This study was applicable in terms of purpose and research method was descriptive-correlational. The statistical population was senior managers and deputies of knowledge-based companies in Tehran. By simple random sampling method, 400 people were selected as the sample with a return rate of 388 people. The research tool was a researcher-made questionnaire. To test the research hypotheses, structural equation tests and partial least squares method have been used.

Results: The results of this study showed that there is a positive and significant relationship between evaluating the performance of knowledge staff with individual outputs and organizational outputs. Also, the moderating effect of participatory ethical culture on the relationship between performance appraisal of knowledge employees and individual outputs as well as the relationship between performance appraisal of knowledge staff and organizational outputs has been confirmed.

Conclusion: When there is a culture of participatory ethics in an organization, performance appraisal, although it increases organizational outcomes, further leads to improved individual outcomes.

Keywords: Participatory ethical culture, Performance evaluation, Individual outcome, Organizational outcome

*Corresponding Author: Email: s.salajeghe@iauk.ac.ir

Received: 13 Jan 2021

Accepted: 16 Feb 2021

50

Available at: www.ijethics.com 


\section{Introduction}

Knowledge employees are the strength of knowledge-based companies that cannot be imitated by competitors. Due to the movement of societies from traditional to modernization, knowledge-based companies based on the use of knowledge forces have emerged (1). A look at these changes has led employees who initially used their manual forces to rely on their ideas, knowledge and skills today (2). Performance appraisal is one of the functions of human resource management that has been mentioned in various texts such as human resource development, determining training needs, reducing mental gaps between managers and employees or creating a teamwork environment with competitive disadvantages. In all of these topics, there are a variety of goals for evaluating performance in specific research that occur under specific circumstances (3). There has been relatively comprehensive research on ethical issues in organizations. Ethics (work ethic and participatory ethics) depend on current evaluations in organizational, work, and social environments; in fact, current evaluations build the norms and beliefs of current ethics. Thus, ethics in general may be seen as a description of society.

Work ethics is considered as the distance between the ethical behavior of the company and the market perception of the ethics of the company. One of the topics in the field of work ethics is the culture of participatory ethics. Participatory ethics has an intrinsic effect on good work performance. In particular, participatory ethics is considered as the gap between the ethical behavior of management and employees' perception of the ethical behavior of the manager in work performance. There is a close relationship between work ethic and participatory ethics. Work ethic is based on the extra-organizational approach of the company's work performance and is a sub-branch of applied ethics, while corporate ethics has a completely opposite perspective and is based on the intra-organizational approach. Extra-organizational approach means that the results of the company's ethical behavior are determined by external sources in the market such as customers, suppliers, competitors and the government (4).

Participatory ethical culture can be considered as a category of culture that while individuals participate in all stages from the beginning of decision making to implementation and evaluation of actions, how employees participate based on ethical principles such as responsibility at the individual, group, organizational and be extra-organizational. The results of using this partnership at the individual level are increasing the level of creativity and innovation, increasing job satisfaction, creating a team spirit, self-confidence and increasing motivation, developing skills and increasing the level of knowledge of individuals (5) Some researchers (6) found that employees' ethical beliefs, which are a subset of their ethical culture, have a significant effect on their in-role and extra-role performance. In this study, work ethics is a set of values and norms that employees use while working. According to what has been said, participatory ethical culture is a kind of values, assumptions and beliefs that are determined by external stakeholders and influential factors such as customers and competitors.

With the studies conducted, research in the field of performance appraisal has been done more around identifying the parameters and variables of performance appraisal, or in other words, more on how it works and the effective factors or results of using performance appraisal in research have not been studied (7). Also, research has less examined the role of participatory ethical culture in relation to performance appraisal and individual and organizational consequences. Although performance appraisal plans are formulated and implemented separately, these plans must be integrated with individual and team goals and the process of group participation and sharing of responsibilities and mutual expectations must be identified in order to achieve successful results. Due to this, the present study 
was formed with the aim of analyzing the relationship between participatory ethical cultures and evaluating the performance of knowledge employees and its outputs in knowledge-based companies in Tehran. And the following four hypotheses were examined:

Hypothesis 1. Performance appraisal has a direct and significant effect on individual outcomes.

Hypothesis 2. Performance appraisal has a direct and significant effect on organizational outcomes.
Hypothesis 3. Participatory ethics culture has a moderating effect on the relationship between performance appraisal and individual outcomes.

Hypothesis 4. Participatory ethics culture has a moderating effect on the relationship between performance appraisal and organizational outcomes. In the following, the theoretical model of the research is shown in Figure 1.

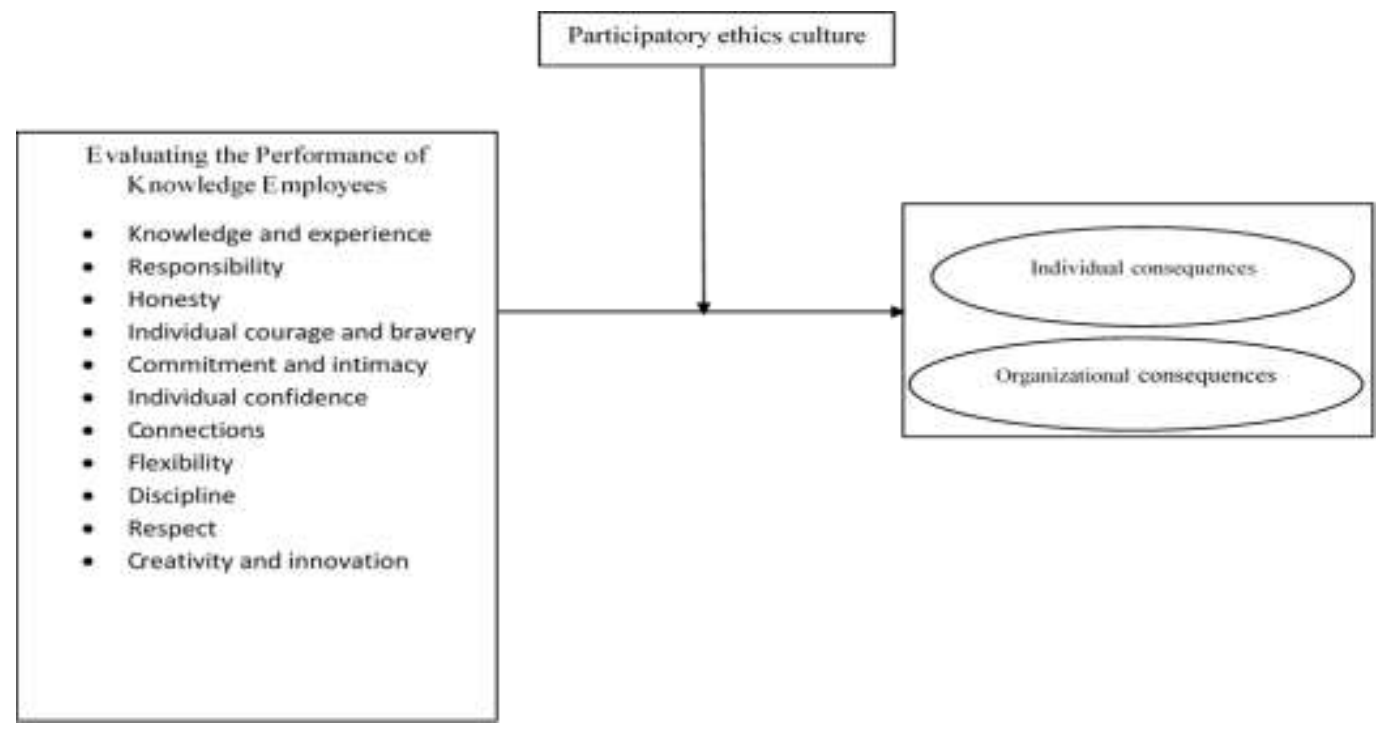

Fig. 1: Theoretical model of research

\section{Material \& Methods}

This research is applied in terms of purpose and descriptive-correlation in terms of method. The statistical population of the study is human resources experts and managers of knowledge-based companies in Tehran. The number of knowledge-based companies operating in Tehran is 1525 companies and the minimum number of employees and managers of these companies is 3050 people. Some researchers (8) have stated that the number of statistical sample members that are suitable for data analysis is between 300 and 500. In this study, 400 people among managers and human resources experts of companies were selected as a sample by simple random sampling method (return rate was 388 people whose demographic characteristics are presented in Table 1). The research tool was a re- searcher-made questionnaire. The research questionnaire consisted of two parts. The first part asked demographic questions such as gender, marital status, etc. (Table 1) and the other part included standard questions with a 5-point Likert scale. In that, the variable of evaluating the performance of knowledge employees with 31 questions, the variable of participatory ethical culture with 13 questions and the variable of consequences were measured using 16 questions. Its validity has been confirmed by using content validity and structural validity and its reliability has been confirmed by using Cronbach's alpha test and composite reliability. SPSS22 and Smart PLS software were used to analyze the data and structural equation modeling was used to test the hypotheses. 
Table 1: Results of descriptive statistics of research

\begin{tabular}{|c|c|c|c|}
\hline Variables & Range & No & Percentage \\
\hline \multirow{2}{*}{ Gender } & Male & 244 & 63 \\
\hline & Female & 144 & 37 \\
\hline \multirow{3}{*}{ Age } & Under 29ys & 94 & 24 \\
\hline & $30-39 \mathrm{ys}$ & 187 & 48 \\
\hline & Up to 39ys & 107 & 28 \\
\hline \multirow{3}{*}{ Education } & B.A. \& less & 252 & 65 \\
\hline & M.A & 73 & 18 \\
\hline & Ph.D. & 63 & 17 \\
\hline \multirow{2}{*}{ Marriage } & Single & 238 & 61 \\
\hline & Married & 150 & 39 \\
\hline \multicolumn{2}{|c|}{ Total } & 388 & 100 \\
\hline
\end{tabular}

\section{Results}

Questionnaire reliability and validity and structural model fit

In order to determine the reliability of the tool used, the internal compatibility test was used. One of the most widely used methods for evaluating the reliability of measurement models is to examine internal consistency. Internal consistency analysis follows the proposed method of comparing the three compatibility indices of composite reliability, Cronbach's alpha and the mean variance extracted with a critical value. Table (2) shows the coefficients of the internal compatibility indices. All composite reliability coefficients and critical over-reliability are 0.7 and all extracted mean variance is more than 0.5 . As a result, it can be said that the reliability of measurement models and convergent validity is acceptable.

Table2: Mean variance extracted and reliability of questionnaire components

\begin{tabular}{|c|c|c|c|c|}
\hline Variables & Dimension & $\begin{array}{l}\text { Composite } \\
\text { reliability }\end{array}$ & Cronbach's alpha & $\begin{array}{l}\text { Average variance } \\
\text { extracted }\end{array}$ \\
\hline \multirow{11}{*}{$\begin{array}{l}\text { Evaluate employee } \\
\text { performance }\end{array}$} & Knowledge and experience & $0 / 763$ & $0 / 778$ & $0 / 774$ \\
\hline & responsibility & $0 / 811$ & $0 / 808$ & $0 / 703$ \\
\hline & Honesty & $0 / 750$ & $0 / 763$ & $0 / 759$ \\
\hline & Individual courage and bravery & $0 / 743$ & $0 / 753$ & $0 / 719$ \\
\hline & Commitment and intimacy & $0 / 729$ & $0 / 738$ & $0 / 738$ \\
\hline & Individual confidence & $0 / 735$ & $0 / 741$ & $0 / 729$ \\
\hline & connections & $0 / 739$ & $0 / 733$ & $0 / 741$ \\
\hline & flexibility & $0 / 741$ & $0 / 762$ & $0 / 727$ \\
\hline & Discipline & $0 / 744$ & $0 / 749$ & $0 / 738$ \\
\hline & Respect & $0 / 751$ & $0 / 769$ & $0 / 789$ \\
\hline & creativity and innovation & $0 / 768$ & $0 / 774$ & $0 / 812$ \\
\hline \multicolumn{2}{|c|}{ Participatory ethical culture } & $0 / 823$ & $0 / 841$ & $0 / 843$ \\
\hline \multirow{2}{*}{ Consequences } & Individual & $0 / 763$ & $0 / 771$ & $0 / 728$ \\
\hline & Organizational & $0 / 758$ & $0 / 802$ & $0 / 709$ \\
\hline
\end{tabular}

After collecting information, in order to determine to what extent each measurement index (items) is acceptable for measuring and evaluating hidden variables, it is first necessary to evaluate them using confirmatory factor analysis. The results of confirmatory factor analysis presented in table 3 show that all questions for measuring hidden variables are at a desirable level and can measure and evaluate hidden variables well. 
Table3: Standard coefficients and significant numbers and percentage of research questions

\begin{tabular}{|c|c|c|c|c|c|c|c|c|c|}
\hline variable & Question & $\begin{array}{c}\text { Standard co- } \\
\text { efficient }\end{array}$ & $\mathrm{t}$ value & $p$ values & variable & Question & $\begin{array}{l}\text { Standard } \\
\text { coefficient }\end{array}$ & $t$ value & $p$ values \\
\hline \multirow{12}{*}{$\begin{array}{c}\text { Evaluate } \\
\text { employee } \\
\text { perfor- } \\
\text { mance }\end{array}$} & Q1 & 0.630 & 4.898 & 0.000 & \multirow{31}{*}{$\begin{array}{l}\text { Partici- } \\
\text { patory } \\
\text { ethical } \\
\text { culture }\end{array}$} & Q1 & 0.633 & 7.106 & 0.000 \\
\hline & Q2 & 0.679 & 5.048 & 0.000 & & Q2 & 0.606 & 7.633 & 0.000 \\
\hline & Q3 & 0.645 & 2.881 & 0.000 & & Q3 & 0.619 & 7.058 & 0.000 \\
\hline & Q4 & 0.623 & 7.192 & 0.000 & & Q4 & 0.890 & 6.948 & 0.000 \\
\hline & Q5 & 0.509 & 7.112 & 0.000 & & Q5 & 0.733 & 6.274 & 0.000 \\
\hline & Q6 & 0.673 & 3.481 & 0.000 & & Q6 & 0.730 & 6.238 & 0.000 \\
\hline & Q7 & 0.661 & 2.822 & 0.000 & & Q7 & 0.827 & 6.813 & 0.000 \\
\hline & Q8 & 0.656 & 3.865 & 0.000 & & Q8 & 0.653 & 6.097 & 0.000 \\
\hline & $\mathrm{Q}^{9}$ & 0.802 & 7.069 & 0.000 & & Q9 & 0.759 & 6.214 & 0.000 \\
\hline & Q10 & 0.818 & 6.271 & 0.000 & & Q10 & 0.677 & 4.346 & 0.000 \\
\hline & Q11 & 0.770 & 6.450 & 0.000 & & Q11 & 0.678 & 6.970 & 0.000 \\
\hline & Q12 & 0.686 & 6.543 & 0.000 & & Q12 & 0.853 & 6.453 & 0.000 \\
\hline \multirow{5}{*}{$\begin{array}{l}\text { Output at } \\
\text { the indi- } \\
\text { vidual } \\
\text { level }\end{array}$} & Q1 & 0.882 & 8.980 & 0.000 & & Q13 & 0.660 & 7.992 & 0.000 \\
\hline & Q2 & 0.893 & 10.134 & 0.000 & & Q14 & 0.842 & 6.792 & 0.000 \\
\hline & Q3 & 0.549 & 7.238 & 0.000 & & Q15 & 0.828 & 7.993 & 0.000 \\
\hline & Q4 & 0.618 & 7.105 & 0.000 & & Q16 & 0.830 & 4.428 & 0.000 \\
\hline & Q5 & 0.679 & 7.088 & 0.000 & & Q17 & 0.847 & 4.540 & 0.000 \\
\hline \multirow{11}{*}{$\begin{array}{c}\text { Output at } \\
\text { the organ- } \\
\text { izational } \\
\text { level }\end{array}$} & Q1 & 0.833 & 7.925 & 0.000 & & Q18 & 0.624 & 7.001 & 0.000 \\
\hline & Q2 & 0.690 & 6.870 & 0.000 & & Q19 & 0.617 & 7.993 & 0.000 \\
\hline & Q3 & 0.646 & 6.759 & 0.000 & & Q20 & 0.676 & 6.191 & 0.000 \\
\hline & Q4 & 0.789 & 7.895 & 0.000 & & Q21 & 0.707 & 7.018 & 0.000 \\
\hline & Q5 & 0.674 & 6.307 & 0.000 & & Q22 & 0.607 & 7.375 & 0.000 \\
\hline & Q6 & 0.710 & 7.765 & 0.000 & & Q23 & 0.624 & 7.279 & 0.000 \\
\hline & Q7 & 0.668 & 6.678 & 0.000 & & Q24 & 0.727 & 7.353 & 0.000 \\
\hline & Q8 & 0.758 & 7.948 & 0.000 & & Q25 & 0.741 & 4.452 & 0.000 \\
\hline & Q9 & 0.709 & 7.735 & 0.000 & & Q26 & 0.528 & 7.863 & 0.000 \\
\hline & Q10 & 0.763 & 7.760 & 0.000 & & Q27 & 0.797 & 6.373 & 0.000 \\
\hline & Q11 & 0.644 & 6.181 & 0.000 & & Q28 & 0.600 & 4.383 & 0.000 \\
\hline & & & & & & Q29 & 0.625 & 6.185 & 0.000 \\
\hline & & & & & & Q30 & 0.650 & 7.611 & 0.000 \\
\hline & & & & & & Q31 & 0.621 & 7.058 & 0.000 \\
\hline
\end{tabular}

\section{Correlation analysis of research variables}

Pearson correlation coefficient measures the degree of linear correlation between two random variables. The value of this coefficient varies from 1 to 1 , with "1" meaning complete positive correlation, "0" meaning no correlation, and "-1" meaning complete negative correlation. As the results in table (4) show. There is a positive and significant relationship between all research variables.

\section{Table4: Pearson correlation coefficient to in- vestigate the relationship between research variables}

\begin{tabular}{|l|l|l|l|l|}
\hline \multicolumn{7}{|c|}{1} & 2 & 3 & 4 \\
\hline Participatory ethical culture & 1 & & & \\
\hline Individual consequences & $0 / 678$ & 1 & & \\
\hline
\end{tabular}

\begin{tabular}{|l|l|l|l|l|}
\hline Organizational consequences & $0 / 709$ & $0 / 714$ & 1 & \\
\hline Evaluation of performance & $0 / 769$ & $0 / 748$ & $0 / 692$ & 1 \\
\hline
\end{tabular}

\section{Structural Equation Modeling (Research Structural Model)}

One type of relationship between latent variables in a structural equation model is the direct effect type. The structural model examines the relationships between exogenous and endogenous secretions. In the following model, the performance evaluation variable is an exogenous and independent latent variable. The variable of participatory ethical culture is the endogenous and moderating variable and the variable of individual and organizational consequences is the latent endogenous and dependent variable. 


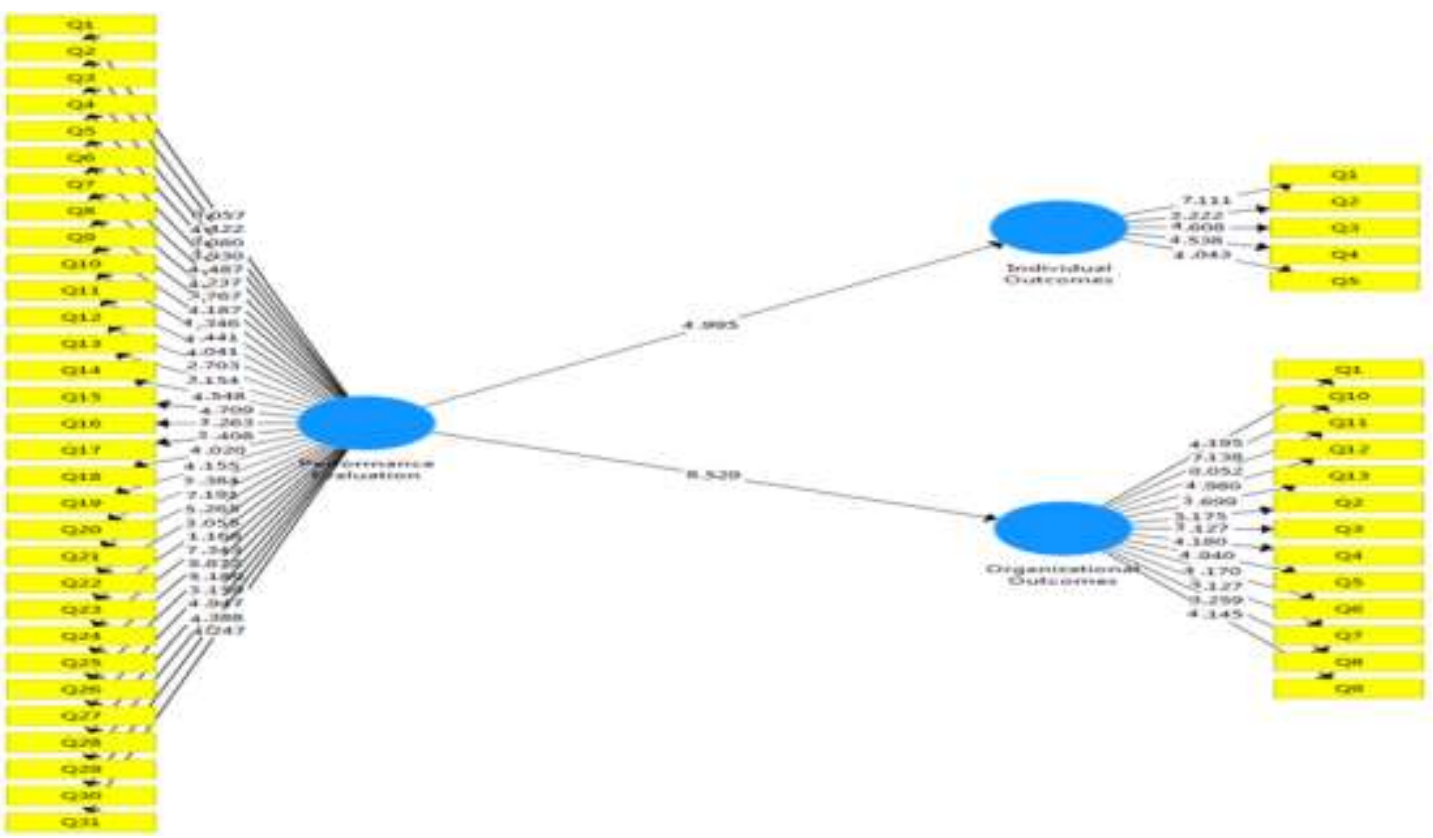

Fig. 2: Investigation of the model in the significant case of T-VALUE number without modulator effect

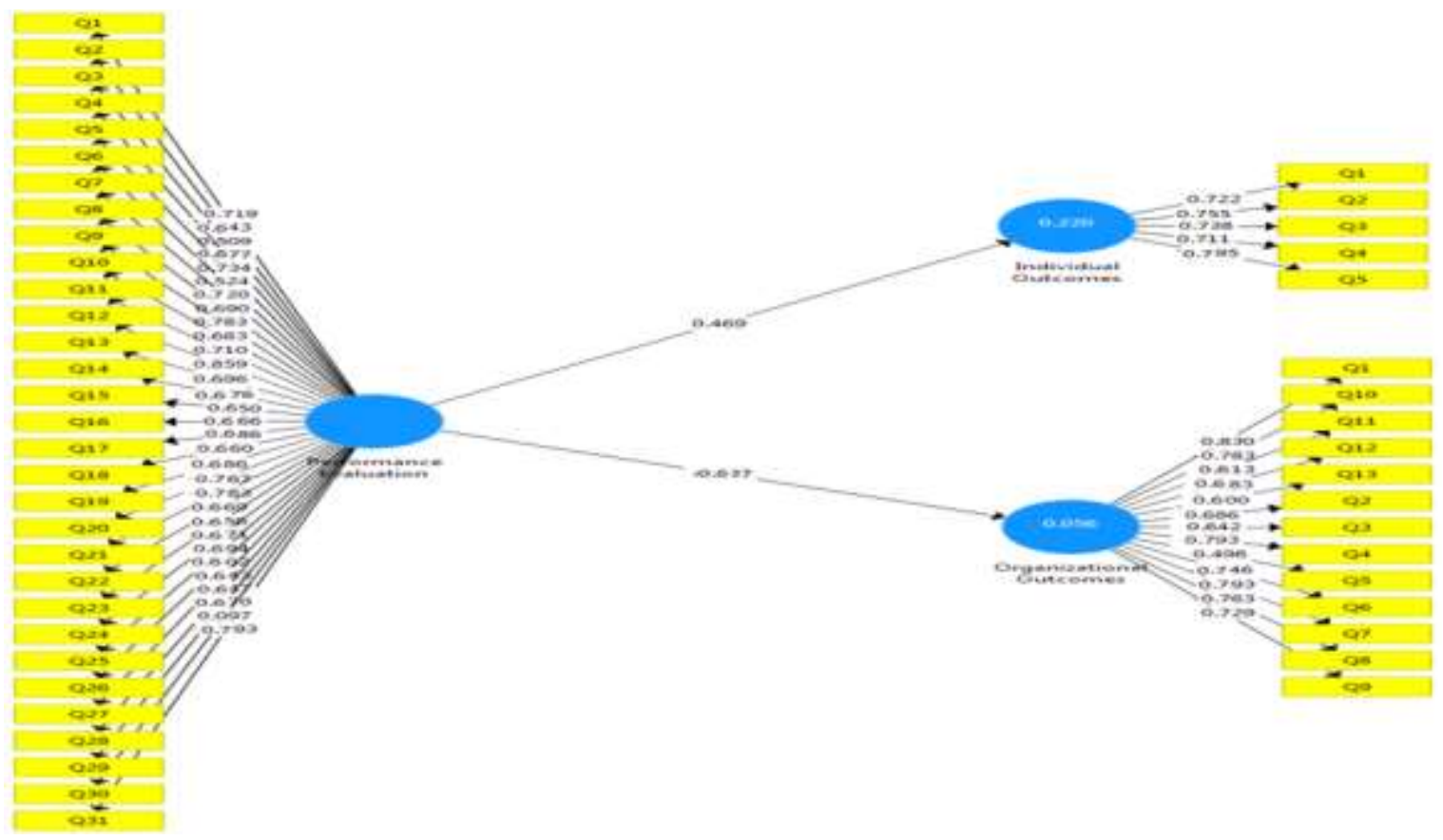

Fig.3: Investigation of the model in the path coefficient mode without the moderator effect 


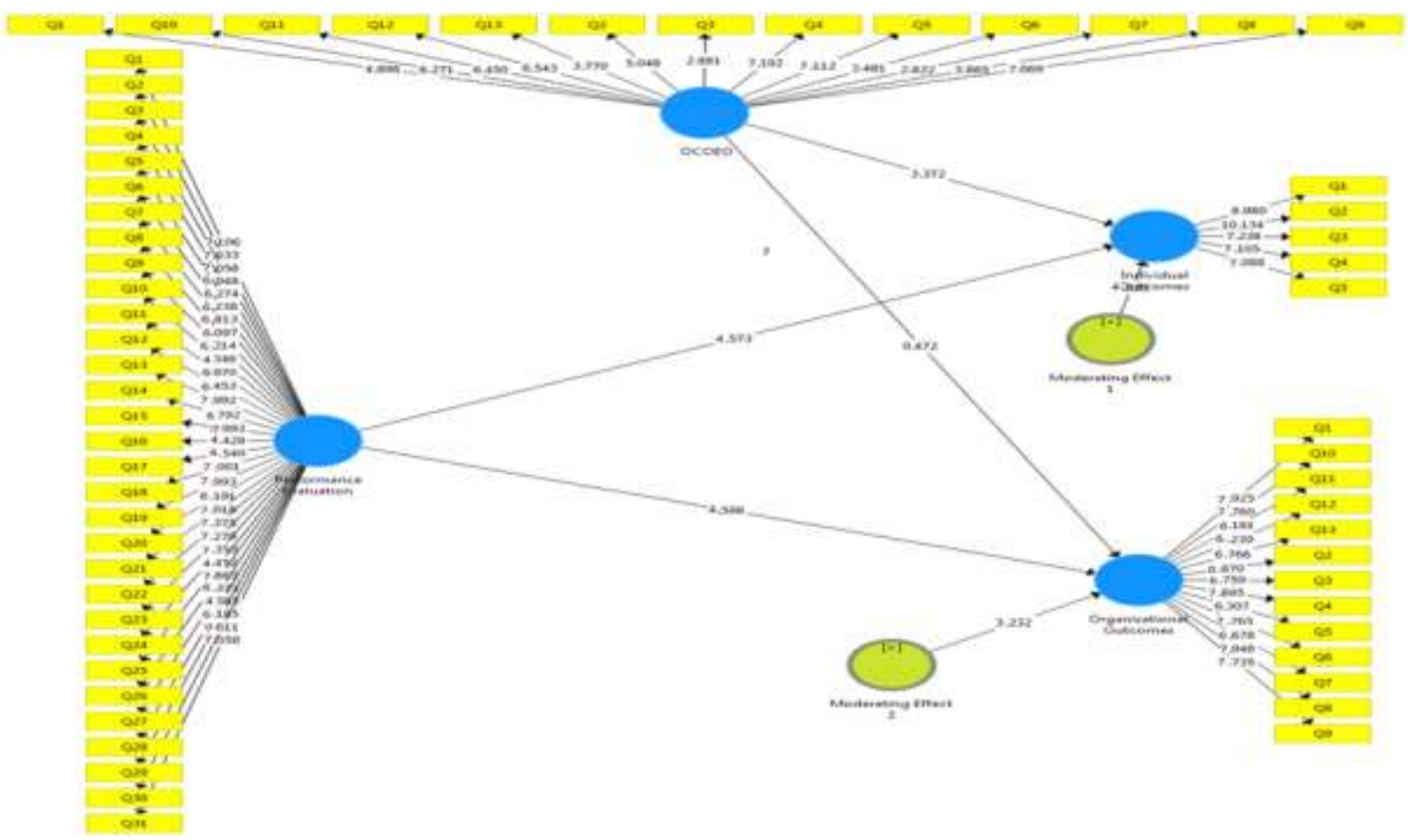

Fig.4: Investigation of the model in the significant case of T-VALUE number with the moderating effect of participatory ethical culture

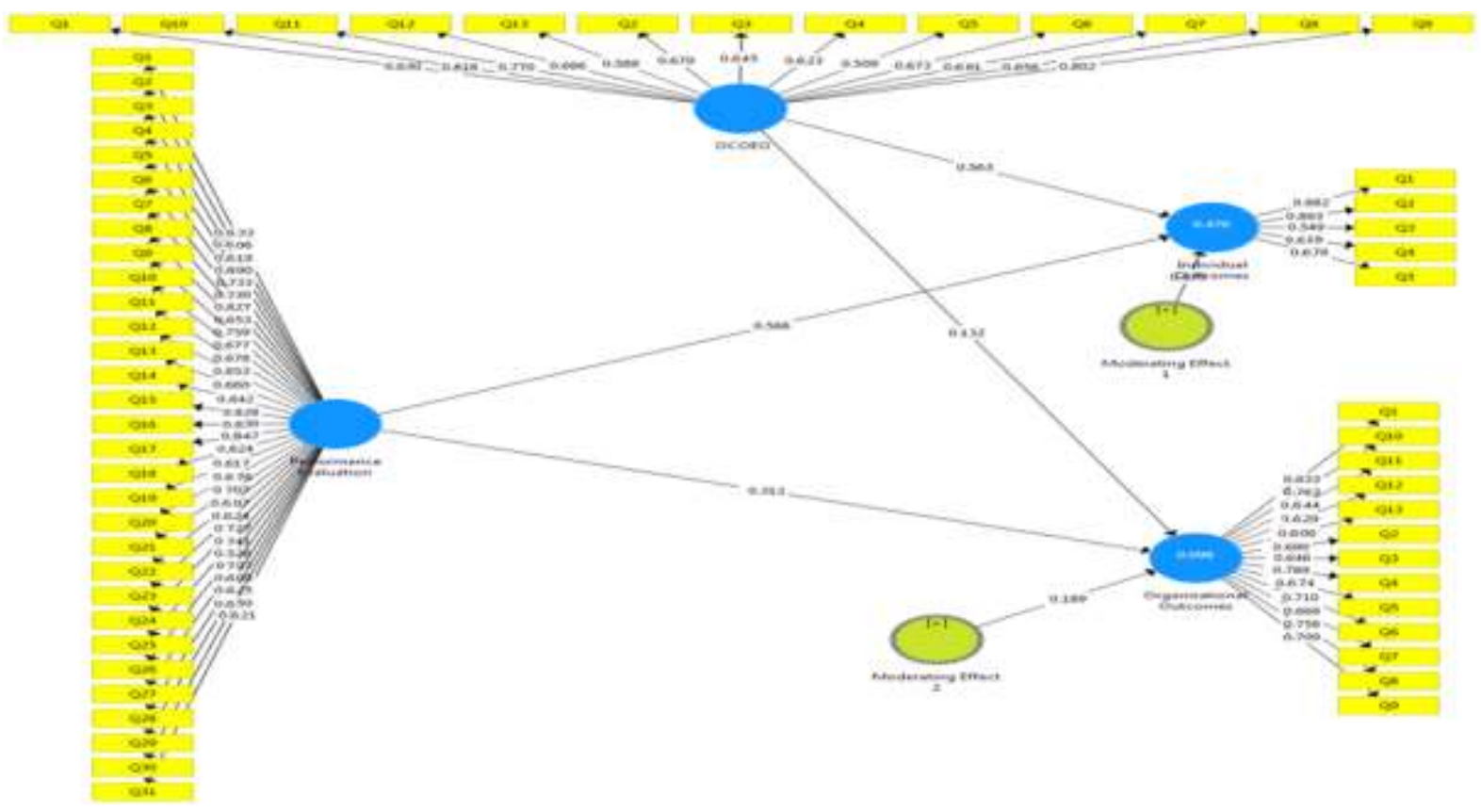

Fig. 5: Investigation of the model in the path coefficient mode with the moderating effect of the variable of participatory ethical culture 
In the table 6 , the statistical results of the hypoth-

eses are presented.

Table 6: Path coefficients and t values for the relationships between variables

\begin{tabular}{|c|c|c|c|c|}
\hline \multicolumn{2}{|c|}{ From } & to & Standard coefficient & t value \\
\hline Evaluation of performance & Individual consequences & $0 / 469$ & $4 / 995$ & Accepted \\
\hline Evaluation of performance & Organizational consequences & $0 / 637$ & $8 / 529$ & Accepted \\
\hline Mediator & Relationship & Standard coefficient & t value & Result \\
\hline participatory ethical culture & $\begin{array}{c}\text { Evaluation of performance \& Individual } \\
\text { consequences }\end{array}$ & $0 / 195$ & $4 / 833$ & Accepted \\
\hline participatory ethical culture & $\begin{array}{c}\text { Evaluation of performance \& Organiza- } \\
\text { tional consequences }\end{array}$ & $0 / 189$ & $3 / 232$ & accepted \\
\hline
\end{tabular}

\section{Discussion}

The purpose of this study is to obtain the consequences of using the performance appraisal system at the individual and organizational levels and also to investigate the effect of participatory ethical culture in these relationships. In the statistical analysis section, it was found that there is a direct and significant relationship between performance evaluation and individual and organizational outcomes. The path coefficient at the level of organizational outcomes is higher than the path of individual outcomes, which indicates a greater and more significant effect of performance appraisal on organizational outcomes. This result is consistent with the results of some studies (9-11). However, with the introduction of the moderator variable of participatory ethical culture, the effect of performance appraisal on individual outcomes has increased. The results obtained in this study are consistent with previous research (12-17). Researchers have also found that the performance appraisal system is not very effective regardless of organizational conditions and culture, and despite the participatory culture that is based on ethical principles, we can expect better individual and organizational outcomes. Interested researchers are encouraged to test the model in other organizations and companies and use semi-structured interviews to find a native performance appraisal model for the case under study..

\section{Conclusion}

The culture of any organization is directly related to the common traditions, beliefs and expectations of individuals, and in general, culture can be considered a set of beliefs, feelings, symbols, behaviors and characteristics that make up an organization. Different experts have divided organizational culture into different categories and patterns. Among them, the concept of participatory ethical culture is seen as an important model in work ethic. When there is a culture of participatory ethics in an organization, performance appraisal as a process of identifying, observing and improving human performance in organizations, although it increases organizational outcomes, further leads to improved individual outcomes as employees evaluate performance. They do not see negative judgment from their superiors, and they are more likely to understand that the purpose of performance appraisal is to increase one's self-satisfaction and commitment.

\section{Ethical Consideration}

Ethical issues (including plagiarism, informed consent, misconduct, data fabrication and/or falsification, double publication and/or submission, redundancy, etc.) have been completely observed by the authors. 


\section{References}

1. Hu R (2014). Migrant knowledge workers: An empirical study of global Sydney as a knowledge city. Expert Systems with Applications, 41(12): 5605-5613.

2. Afkhami-Ardakani M, Khalili-SadrAbad A (2012). Investigating the relationship between personality factors and the silence of knowledge workers. Journal of General Management Researhes, 5(18): 65-83. (In Persian).

3. Akhavan Kharazian M, Shahbazi MM, Fatehi M (2017). Evaluate the performance of the knowledge staff of the $\mathrm{R} \& \mathrm{D}$ unit in terms of outsourcing. Joumal of Production and Operations Management, 8(14): 139-156. (In Persian).

4. Ghovat-Din MS (2016). The model of corporate ethics in total quality management (TQM). Ethics in Science and Technology, 10 (3): 111-120. (In Persian).

5. Panigrahi SK, Al-Nashash HM (2019). Quality work ethics and job satisfaction: An empirical analysis. Quality - $A c$ cess to Success, 20(168):41-47

6. Rezaei Kelidbari HR, Fadaei M, Ebrahimi P (2016). The role of ethical leadership on employee performance in Guilan University of medical sciences. Social \& Behavioral Sciences, 230: $463-470$.

7. Salamat S, Mirsepasi N, Reshadatjoo H (2019). Designing a human resource performance management system in order to improve economic productivity (case study: Ayandeh Bank). Journal of Economics and Urban Management, 7(3): 125-141. (In Persian).

8. Rokhman W (2010). The effect of Islamic work ethics on work outcomes. EJBO-Electronic Journal of Business Ethics and Organization Studies, 2(1).

9. Brown M, HyattD, Benson J (2010). Consequences of the performance appraisal experience. Personnel Review, 39(3):375-396.
10. Samwel JO. (2018). An assessment of the impact of performance management on employee and organization performance-evidence from selected private organizations in Tanzania. International Journal of Human Resource Studies, 8(3):199.

11. Tagliabue M, Sigurjonsdottir SS, Sandaker I (2020). The effects of performance feedback on organizational citizenship behavior: a systematic review and meta-analysis. European Journal of Work and Organizational Psychology, 29(6).

12. Shafiee F, Kalantari M, Zolfaghari-Zaferani R (2018). The effect of professional ethics on job performance with regard to the mediating role of religiosity in work (Case study: education teachers in Hamadan province). Journal of Research in Educational Systems, 986-1008. (In Persian).

13. Kandula SR (2006). Performance management. Strategies, interventions, drivers. PHI Learning Pvt. Ltd, Dehli/India.

14. Asamany A, Shaorong S (2018). The ripple effects of performance management on employees? perceptions and affective commitment among small and medium scale enterprises (SMEs). International Journal of Business Administration, 9(1): 55-63.

15. Maina JM (2015). Effect of performance management system on employee performance: A study of food and agriculture organization. [Ph.D. thesis]. United States International University, Africa.

16. Mogheli A, Seyyed Javadin SR, Ahmadi SA, Alavi A (2013). Islamic work ethics and organizational citizenship behavior model with job role: A case study of Isfahan University of Medical Sciences, Iran. Health Information Management, 20(2):1-10. (In Persian).

17. Tufail U, Ahmad MS, Ramayah T, Jan FA, Shah IA (2017). Impact of Islamic work ethics on organizational citizenship behaviors among female academic staff: the mediating role of employee engagement. Applied Researh in Quality of Life, 12(3): 693-717. 